\title{
Limit Orders, Asymmetric Information, and the Formation of Asset Prices with a Computerized Specialist
}

\author{
Michael R. Baye, Ann Gillette, and Casper G. de Vries
}

Received June 30, 1992; revised version received September 16, 1993

We analyze the existence of equilibrium in an asset market under asymmetric information. Price formation is modeled as a bilateral sealed bid auction where uninformed and informed traders submit limit orders to a computerized specialist. The computerized specialist is programmed to sell to the highest bidder and buy from the seller asking the lowest price. We show that this mechanism - which is designed to model the Globex and RAES trading institutions used in Chicago, London, New York, Paris, and Germany - yields an equilibrium in which the bid-ask spread is endogenously random and the passive specialist earns nonnegative profits.

\section{Introduction}

There has been a recent surge in theoretical and empirical research on limit orders (Easley and O'Hara, 1991; Cohen et al., 1986; O'Hara and Oldfield, 1986; Rock, 1990; Kyle, 1989; Berkman, 1990). To our knowledge there does not exist theoretical research on limit orders in computerized financial markets. This is surprising, given the growing relevance of computerized markets that involve limit orders. For instance, Domowitz (1990) notes that the Chicago Mercantile Exchange's (CME) computerized trading in futures (the Globex system) only accepts limit orders; market orders are not accepted "after hours" when the Globex system is matching buyers and sellers of futures contracts. Similarly, the Retail Automated Exchange System (RAES) used by the Chicago Board of Options Exchange (CBOE) matches the buyer with the highest limit price with the seller with the lowest, to consummate an exchange. The purpose of this paper is to model this type of computerized trading environment. We are particularly interested in the implications for the existence of equilibrium under asymmetric information, the ex post information content of bid and ask prices, and the expected 
profits eamed by traders and the specialist. To put our model in context, it is useful to present a brief overview of the related literature.

Following Grossman and Stiglitz (1980), much of the literature uses a Walrasian model of price determination to examine financial market equilibrium. In a Walrasian equilibrium, traders submit a quantity order to the "Walrasian Auctioneer." These orders accumulate, and all trades take place at the price such that excess demand is zero. However, financial assets are traded in a multitude of ways throughout the world, and the Walrasian framework is not consistent with most modern computerized markets. An emerging literature on the microstructure of financial markets studies the exchange of assets under specific trading mechanisms and intermediaries. The automation of trading mechanisms and the rapid evolution of asset exchanges world-wide has motivated this research to focus on the implications of market design - how trading mechanisms and markets should be structured (cf. Easley and O'Hara, 1992). Importantly, as Madhavan (1992) has noted, models of asset exchange which depict institutional detail and strategic behavior often exhibit equilibria and prices quite different from that attained in a Walrasian market.

Some of the existing literature (cf. Glosten and Milgrom, 1985) considers markets characterized by a two-price (bid and ask) equilibrium. In this class of models, the bid-ask spread is strategically set by a specialist. Traders on each side of the market take the resulting prices (bid or ask) as given. ${ }^{1}$ Cohen et al. (1986), however, find that the bid-ask spread is largely determined by the limit orders of traders on each side of the market. Rock (1990) examines the interaction of the limit order book with a strategic specialist and finds that the specialist can advantageously use his order-size information. This adverse selection problem, coupled with the increasing sophistication of automated processes, has lead exchanges to investigate the potential for replacing or complementing the role of the traditional specialist with a passive computerized specialist. ${ }^{2}$

Order form also varies among exchanges, ${ }^{3}$ and as noted by Easley

1 Alternatively, Copeland and Galai (1983) assume that the specialist trades aggressively to earn profits from liquidity transactors, while he loses to traders with inside information.

2 For example, the Arizona Stock Exchange is a completely computerized call market where traders submit only limit orders; RAES, used by the CBOE, operates in tandem with options floor trading and uses only small public orders and marketable limit orders. See Domowitz (1990) for the mechanics of automated execution systems.

3 The Arizona Stock Exchange and Globex use exclusively limit orders, 
and O'Hara (1991), this affects the transmission of information into security prices. With asymmetrically informed traders they find that when price-contingent orders are allowed, the specialist sets a larger spread and prices adjust faster. In terms of efficiency, Easley and O'Hara find that price-contingent orders are not the problem, but rather uncertainty over the size and structure of orders. ${ }^{4}$

This overview makes it clear that the outcome of trading and nature of financial market equilibrium depends critically on the trading mechanism. The present paper differs from the existing literature in two fundamental respects. Unlike the Walrasian model, a trader in our model submits a limit price (either a bid or an ask) instead of a quantity, and thus there is a type of two-price equilibrium. Secondly, in contrast to the extant literature on the bid-ask spread, but corresponding to the institutional setup of the Globex exchange, the spread in our model is not set by a strategically motivated specialist; it is determined by limit orders submitted to a computer - a passive, non-strategic specialist.

The next section presents a simple model of a computerized trading environment that closely parallels the Globex and RAES markets. We then examine equilibrium and the information content of prices in these types of computerized markets when some market participants enjoy better information than others. In equilibrium, it turns out that the computerized specialist may earn positive economic profits - despite its passive behavior. We conclude with a summary of the key implications of this type of computerized market environment.

\section{Assumptions and Notation}

The asset market is modeled as a simultaneous-move one-shot game, where asymmetrically informed buyers and sellers compete in prices for the right to buy or sell one unit ${ }^{5}$ of an asset through a specialist. The specialist is a computer that is programmed to accept limit orders and match buyers and sellers. We do not attempt to model dynamic trading strategies, whereby insiders can potentially manipulate prices over time to earn profits. This is consistent with most papers in the litera-

whereas RAES and NASDAQ's Small Order Execution System (SOE) use both limit and market orders.

4 Some automated systems, such as RAES and SOE, restrict the choice of order size.

5 Easley and O'Hara (1987) examine an adverse selection problem in trading arising from their assumption that informed traders prefer to trade larger amounts of securities at any given price. 
ture, including Grossman and Stiglitz (1980) and Gould and Verrecchia (1985).

Our model is summarized by 7 assumptions. The first 5 assumptions explicitly indicate the nature of the asymmetric information in the market, while the remaining 2 summarize the nature of the computerized market and the algorithm underlying the computerized specialist.

Assumption 1: An asset will yield a payoff of $v$ dollars at some specified future date. It is assumed that $\operatorname{Prob}(y=0)=\frac{1}{2}$ and $\operatorname{Prob}(v=1)$ $=\frac{1}{2}$.

To be concrete, one can think of the asset as a zero-coupon bond with a maturity value of one thousand dollars if the company does not default. and zero otherwise. The assumption that there is a fifty-fifty chance of default is made purely for notational convenience. ${ }^{6}$

Assumption 2: All traders are risk neutral.

This assumption allows us to focus on the role of asymmetric information, not asymmetries in risk preferences, in determining market equilibrium. It is now well-known (Spiegel and Subrahmanyam, 1992) that the presence of risk-averse hedgers can give rise to the existence of equilibrium in a Kyle (1985) type model, even in the absence of "noise traders." An open question is whether an equilibrium can exist in the absence of noise traders and risk asymmetries - a question answered in the affirmative below.

Since we assume all traders have identical risk preferences, in order to provide a basis for trade we need a source of heterogeneity in valuations of the asset. We do so by assuming:

Assumption 3: Buyers have a discount factor of unity; sellers have a discount factor of $\delta \leq 1$.

If all traders valued the asset identically ( $\delta=1)$, there would be no basis for trade, and therefore no need for an asset market. But if $\delta<1$, buyers value the asset more than sellers, and there are potential gains

6 More generally, the zero-one structure may be viewed as the range of the indicator function mapping sets of events such as increases and decreases in an asset price. 
to exchange. When $\delta<1$, one can view buyers as young people who wish to invest in their retirement, and sellers as old people who wish to sell their share of an asset for retirement. The old generation is willing to sell the asset at a discount (lower value) relative to its future value, in order to have cash today. Under this interpretation, buyers are endowed with cash and sellers are endowed with one unit of the asset; hence we are not attempting to explain how traders determine whether to participate in the market as buyers or sellers. ${ }^{7}$

In addition to the asymmetries among buyers and sellers when $\delta<1$, we also allow for differences in information among traders. In particular:

Assumption 4: A fraction $\beta$ of the buyers are informed (and know with certainty the value of $v$ ). The fraction $(1-\beta)$ of the buyers are uninformed (and know only the probability distribution over $v$ ).

Assumption 5: A fraction $\alpha$ of the sellers are informed (and know with certainty the value of $v)$. The fraction $(1-\alpha)$ of the sellers are uninformed (and know only the probability distribution over $v$ ).

Notice that when $\beta=\alpha=1$ or $\beta=\alpha=0$, our model collapses to one of symmetric information. But when $\alpha, \beta \in(0,1)$, some traders enjoy better information than others. We will thus be able to examine how the degree of asymmetric information affects equilibrium and the profits of traders and the specialist. For now, we assume that the number of informed and uninformed market participants is exogenous. Later, we allow information to be obtained at some cost, and endogenously determine the number of informed and uninformed market participants.

Our next assumption highlights the market mechanism that facilitates exchange. This mechanism captures important features of computerized markets like the Globex and RAES exchanges.

Assumption 6: The specialist is a computer program, which accepts limit orders for one block of the asset. The specialist buys the block from the seller with the lowest asking price, and in turn sells it to the buyer with the highest bid price. The computer can accept only two bids and two asks at any instant in time. Bid prices are denoted by $b$, while asking prices are denoted by $a$.

7 See Baye and Cosimano (1990) for a model where traders endogenously determine whether to buy, sell, or hold an asset. 
Assumption 6 reflects the passive role of the specialist (the computer program) that runs modern computerized exchanges like Globex, RAES, and the Arizona exchange. Similar to the Globex and Arizona exchanges, only limit orders are accepted. On the Globex exchange and our model - there are two prices: a bid and an ask price. This represents a departure from market mechanisms where orders accumulate, and are transacted at a single price that equates supply and demand. The assumption that traders are restricted to trading one-unit blocks of the asset is made to capture the practical problems encountered by computerized trading systems. In particular, computerized specialists do not typically buy and sell for their own account, but rather are designed to link buyers and sellers. Consequently, by restricting orders to one-unit blocks (the RAES system restricts index options contracts to 10 and equity options contracts to 5) we do not have to distinguish between "fill or kill" orders, and orders where fractions of the desired trade may be consummated. ${ }^{8}$ Presumably, this is also one of the reasons actual computerized exchanges limit the number of units that can be bought or sold at any instant in time: to simplify the computer program. The assumption that only two buyers and two sellers are on the market at any one instant in time is made purely to simplify notation; none of the qualitative results below differ when an arbitrary (but finite) number of bids and asks are accepted at any instant in time. ${ }^{9}$

Our final assumption characterizes the information enjoyed by traders at the time their limit orders are submitted to the computerized specialist.

Assumption 7: Traders do not know whether they are bidding against an informed or uninformed trader, but have rational expectations about the likelihood of the events. Moreover, the book of limit orders is closed.

This assumption allows us to focus purely on the informational content of bid and ask prices. If the limit order book were open, then traders could condition their bids on the information revealed in the

8 Often so-called "odd lots" are retailed outside of the computerized market (through brokers or banks). This assumption also eliminates the potential adverse selection problem that can arise when traders may vary their quantity orders depending on their information sets.

9 However, the analysis is substantially more complex with more than two bids and asks. In this case there may exist asymmetric equilibria where identical agents use different bid or ask strategies (cf. Baye et al., 1992). 
open books. Since, to our knowledge, ours is the first paper on microstructure that formally models limit orders and asymmetric information in the context of a passive computerized market, we focus here on closed books to determine a benchmark for the information content of bid and ask prices in such a trading institution.

\section{Equilibrium Bid and Asking Prices}

Given the above game of complete but imperfect information, each market trader bases decisions on his own information, the information possessed by other traders on his side of the market, the probability of competing against an informed or uninformed trader, and the probability distribution over the asset value. Traders have rational expectations in the sense that the conditional expectation operators are correct, based on the underlying distributions in equilibrium. This section addresses the existence of equilibrium bid and ask strategies in such a computerized market. The next section examines the implications of the equilibrium strategies for the profits of the traders and the computerized specialist. It also provides sufficient conditions for an equilibrium to exist in the asset market where traders and the specialist all earn nonnegative profits.

If all buyers are informed, a pure-strategy Nash equilibrium exists on the buyer side of the market whereby buyers bid zero when $v=0$ and bid one when $v=1$. In this instance, buyers earn zero economic profits. At the other extreme, if all buyers are uninformed, a pureStrategy Nash equilibrium exists where the buyers bid the expected value of the asset of one-half, since they are risk-neutral. Analogous pure-strategy equilibria exist on the seller side of the market.

Of greater interest is the existence of equilibrium strategies when there is asymmetric information; that is, when some traders are perfectly informed and others only know the probability distribution over $v$. It is easy to verify that, when $0<\alpha<1$ and $0<\beta<1$, there does not exist a Nash equilibrium in pure-strategies. However, we will establish:

Proposition 1: When $0<\alpha<1$ and $0<\beta<1$, there exists a mixedstrategy Nash equilibrium on the buyer and seller sides of the market.

In order to prove this proposition, we first assert the equilibrium strategies, and then use two lemmas to establish that these strategies satisfy the mutual best response property required of a Nash equilibrium. A third lemma examines the shape of the equilibrium mixed strategies. 
Consider first the buy side of the market. Let $F_{\mathrm{u}}(b)$ be the cdf used by an uninformed buyer to randomize his bid. Note that, as the uninformed do not know $v$, they cannot condition their bid on the true value of the asset. On the other hand, the informed can condition their bid on the value of $v$, so let $F_{\mathrm{I}}(b \mid v)$ be the cdf used by an informed buyer when the value of the asset is $v$. By Bellman's principle, if $v=0$, the informed will bid zero, so $F_{\mathrm{I}}(0 \mid v=0)=1$. This makes intuitive sense; if a buyer knows the asset is worthless, he would never bid a positive amount to acquire the asset. The more interesting case for an informed buyer is the equilibrium strategy when $v=1$. For notational simplicity, let $F_{\mathrm{I}}(b) \equiv F_{\mathrm{I}}(b \mid v=1)$ denote the cdf used to randomize bids when $v=1$.

Lemma 1: For $0<\beta<1$, there exists a mixed strategy equilibrium on the buyer side of the asset market. In particular, an uninformed buyer randomizes his bid according to

$$
F_{\mathrm{u}}(b)= \begin{cases}0 & \text { if } b<0 \\ \frac{\beta b}{(1-\beta)(1-2 b)} & \text { if } b \in\left[0, \frac{1-\beta}{2-\beta}\right] \\ 1 & \text { otherwise. }\end{cases}
$$

An informed buyer submits a bid of zero if $v=0$. But if $v=1$ the informed buyer randomizes his bid according to

$$
F_{\mathrm{I}}(b)= \begin{cases}0 & \text { if } b<\frac{1-\beta}{2-\beta}, \\ \frac{1-\beta}{\beta}\left[\frac{1}{(2-\beta)(1-b)}-1\right] & \text { if } b \in\left[\frac{1-\beta}{2-\beta}, \frac{1}{2-\beta}\right], \\ 1 & \text { otherwise. }\end{cases}
$$

Moreover, the expected trading profits of an uninformed buyer are $E \pi_{\mathrm{u}}^{b}=0$, while the expected trading profits of an informed buyer. conditional on his information set, are $E\left[\pi_{I}^{b} \mid v=1\right]=\frac{1-\beta}{2-\beta}$ and $E\left[\pi_{1}^{b} \mid v=0\right]=0$.

Proof: First, note that $F_{\mathbf{v}}$ and $F_{\mathfrak{1}}$ defined in the lemma are well-defined cdf's. Moreover, as there are no mass points in $F_{\mathrm{u}}$ and $F_{\mathrm{I}}$, the probability of a tie is zero. The expected profits to an uninformed buyer of 
using strategy $F_{\mathrm{u}}^{*}$ when the other traders use $F_{\mathrm{I}}$ and $F_{\mathrm{u}}$ are

$$
\begin{aligned}
E \pi_{\mathrm{u}}^{b}= & \int_{0}^{\frac{1-\beta}{2-\beta}}\left\{\beta\left[\frac{1}{2} F_{\mathrm{I}}(b)(1-b)+\frac{1}{2}(-b)\right]\right. \\
& \left.+(1-\beta) F_{\mathrm{u}}(b)\left(\frac{1}{2}-b\right)\right\} \mathrm{d} F_{\mathrm{u}}^{*}(b)=c_{\mathrm{u}} .
\end{aligned}
$$

The first term in curly brackets reflects the probability that an uninformed agent bids against an informed agent, times the expected profits from bidding against an informed agent who uses the asserted mixed-strategy. The second term in brackets is the probability of bidding against another uninformed trader, times the expected profits from bidding against an uninformed agent.

Conditional on $v=1$, the expected profits to an informed buyer using $F_{I}^{*}$ when the other traders use the $F_{I}$ and $F_{u}$ asserted in the lemma are

$$
\begin{aligned}
& E\left[\pi_{\mathrm{I}}^{b} \mid v=1\right] \\
& =\int_{\frac{1-\beta}{2-\beta}}^{\frac{1}{2-\beta}}\left\{\beta F_{\mathrm{I}}(b)(1-b)+(1-\beta) F_{\mathrm{u}}(b)(1-b)\right\} \mathrm{d} F_{\mathrm{I}}^{*}(b)=c_{\mathrm{I}} .
\end{aligned}
$$

We will show that, given that other traders use the strategies in the lemma, no trader has an incentive to choose $F_{\mathrm{u}}^{*}$ and $F_{\mathrm{I}}^{*}$ differently from $F_{\mathrm{u}}$ and $F_{\mathrm{I}}$ defined in the lemma. More precisely, let $i(\mathrm{u})=\left[0, \frac{1-\beta}{2-\beta}\right]$ and $i(I)=\left[\frac{1-\beta}{2-\beta}, \frac{1}{2-\beta}\right]$. We will demonstrate the mutual best response property by establishing the following four claims. Claim (a): the integrand in Eq. (1) is equal to zero for all $b \in i(\mathrm{u}) ; \operatorname{claim}(b)$ : the integrand in Eq. (1) is less than zero for $b \notin i(\mathrm{u})$; claim (c): the integrand in Eq. (2) is equal to $(1-\beta) /(2-\beta)$ for all $b \in i(\mathrm{I})$; and claim $(d)$ : the integrand in Eq. (2) is less than $(1-\beta) /(2-\beta)$ for $b \notin i(\mathrm{I})$.

Proof of claim (a): Note that for $b \in i(\mathrm{u}), F_{\mathrm{I}}(b)=0$. Hence the integrand in Eq. (1), for $b \in i(\mathrm{u})$, is

$$
\begin{aligned}
& -\frac{\beta b}{2}+\frac{1}{2}\left\{(1-\beta)\left[\frac{\beta b}{(1-\beta)(1-2 b)}\right](1-2 b)\right\} \\
= & -\frac{\beta b}{2}+\frac{\beta b}{2}=0=c_{u}
\end{aligned}
$$

for all $b \in i(\mathrm{u})$, as required. 
Proof of claim (b): As negative bids are disallowed, we need only establish that for $b>(1-\beta) /(2-\beta)$, the integrand in $\mathrm{Eq}$. (1) is negative. But for $b>(1-\beta) /(2-\beta), F_{\mathrm{u}}(b)=1$. Hence the integrand is

$$
\begin{aligned}
& \beta\left\{\frac{(1-b)(1-\beta)}{2 \beta}\left[\frac{1}{(2-\beta)(1-b)}-1\right]-\frac{b}{2}\right\} \\
& +\frac{(1-\beta)(1-2 b)}{2}=\frac{1}{2}\left\{\frac{1-\beta}{2-\beta}-b\right\},
\end{aligned}
$$

which is less than zero for all $b>(1-\beta) /(2-\beta)$, as required.

Proof of claim (c): For $b \in i(\mathrm{I}), F_{\mathrm{l}}(b)=0$. Hence when $b \in i(\mathrm{I})$, the integrand in Eq. (2) is

$$
\begin{aligned}
& \beta(1-b) \frac{1-\beta}{\beta}\left\{\frac{1}{(2-\beta)(1-b)}-1\right\}+(1-\beta)(1-b) \\
& =\frac{1-\beta}{2-\beta}=c_{1}
\end{aligned}
$$

for all $b \in i(\mathrm{I})$, as required.

Proof of claim $(d)$ : For $b<(1-\beta) /(2-\beta), F_{\Upsilon}(b)=0$. Hence the integrand in Eq. (2) is

$$
\frac{(1-\beta)(1-b) \beta b}{(1-\beta)(1-2 \beta)}=\frac{(1-b) \beta b}{1-2 b} \equiv \Gamma(b), \text { say . }
$$

But since $(1-\beta) /(2-\beta)<1 / 2, \mathrm{~d} \Gamma(b) / \mathrm{d} b=\beta+\Gamma(b) /(1-2 b)>0$. It follows that $c_{I}>\Gamma(b)$ for $b<(1-\beta) /(2-\beta)$. Similarly, for $b>$ $1 /(2-\beta), F_{\mathrm{u}}=F_{\mathrm{I}}=1$, and the integrand is $\beta(1-b)+(1-\beta) \times$ $(1-b)=1-b<1-1 /(2-\beta)=(1-\beta) /(2-\beta)$, as required.

Given that the other buyers employ $F_{\mathrm{u}}$ and $F_{\mathrm{I}}$ defined in the lemma. claim (a) shows that it does not pay an uniformed buyer to employ a different strategy, $F_{u}^{*}$ on $i(u)$; claim (c) shows that when $v=1$, it does not pay an informed trader to employ a different strategy, $F_{1}^{*}$ on $i$ (I). These two results follow because the integrands are constant on the intervals $i(\mathrm{u})$ and $i(\mathbf{I})$. Claim (b) shows that it is always detrimental for an uninformed bidder to submit a bid outside of $i(u)$ with positive probability. Claim (d) shows that it is always detrimental for an informed bidder to submit a bid outside of $i(1)$ with positive probability. Hence, given that the other buyers randomize according to $F_{\mathrm{u}}$ and 
$F_{\mathrm{I}}$, there are no gains to an agent for choosing some other strategy. This is exactly the requirement for strategies to be Nash equilibrium mixed-strategies.

We now turn to the sell side of the market. Let $G_{\mathrm{u}}(a)$ be the cdf used by an uninformed trader to randomize his asking price. Again, since the uninformed do not know the true value of $v$, they cannot condition their asking price on the true value of the asset. However, the informed can condition their asking prices on the value of $v$, so let $G_{\mathrm{I}}(a \mid v)$ be the cdf used by an informed seller to generate an asking price when the value of the asset is $v$. When $v=1$, the informed will ask $\delta$, so $G_{\mathrm{I}}(a \mid v=1)=1$ (recall that the sellers value the asset at $\delta$ when $v=1)$. Again, for notational simplicity, let $G_{\mathrm{I}}(a)=G_{\mathrm{I}}(a \mid v=0$ ) denote the cdf used by an informed seller to randomize the asking price when $v=0$.

Lemma 2: For $0<\alpha<1$, there exists a Nash equilibrium in mixedstrategies on the seller side of the market. In particular, each uninformed seller randomizes his asking price according to

$$
G_{\mathrm{u}}(a)= \begin{cases}0 & \text { if } a<\frac{\delta}{2-\alpha}, \\ 1-\frac{\alpha(\delta-a)}{(1-\alpha)(2 a-\delta)} & \text { if } a \in\left[\frac{\delta}{2-\alpha}, \delta\right], \\ 1 & \text { otherwise. }\end{cases}
$$

An informed seiler submits an asking price of $\delta$ if $v=1$. But if $v=0$ an informed seller randomizes his bid according to

$$
G_{\mathrm{I}}(a)= \begin{cases}0 & \text { if } a<\frac{\delta(1-\alpha)}{2-\alpha}, \\ \frac{a(2-\alpha)-\delta(1-\alpha)}{\alpha a(2-\alpha)} & \text { if } a \in\left[\frac{\delta(1-\alpha)}{2-\alpha}, \frac{\delta}{2-\alpha}\right], \\ 1 & \text { otherwise. }\end{cases}
$$

Moreover, the unconditional expected trading profits of an uninformed seller are $E \pi_{\mathrm{u}}^{s}=0$, and the expected trading profits of an informed seller, conditional on his information set, are $E\left[\pi_{1}^{s} \mid v=0\right]=\frac{\delta(1-\alpha)}{2-\alpha}$ and $E\left[\pi_{I}^{s} \mid v=1\right]=0$.

Proof: The proof of this lemma is analogous to the proof of Lemma 1, and is thus omitted. 
Most models solve the problem of existence of equilibrium in asset markets characterized by asymmetric information by assuming the Walrasian price contains some exogenous noise (cf. Grossman and Stiglitz, 1980; Kyle 1985). Proposition 1 reveals that the present model also requires "noise" 10 for the existence of an equilibrium, but this noise arises endogenously from the optimal mixed-strategies used by informed and uninformed market participants.

In Fig. 1 we depict graphically the equilibrium mixed-strategies employed by the informed and uninformed on each side of the market. Recall that uninformed traders cannot condition their bid on the value of the asset, but the informed traders can condition their bid on $v$. It is clear that when $v=1$, the bids by informed buyers stochastically dominate the bids of uninformed buyers; similarly, the asking prices of the informed sellers stochastically dominate the asking prices of the uninformed sellers. In contrast, whenever $v=0$, the bids of the uninformed buyers stochastically dominate the bids of the informed buyers, and the asking prices of the uninformed sellers stochastically dominate the asking prices of informed sellers.

As is indicated in Fig. $1, F_{\mathrm{u}}$ and $F_{\mathrm{I}}$ are convex, while $G_{\mathrm{u}}$ and $G_{1}$ are concave. The intuition for this is as follows. First consider the strategy of an informed buyer when $v=1$. In this instance he is sure to win when bidding against the uninformed, but cannot be sure to win when bidding against an informed agent. Competitive forces increase the density with which higher prices are bid, as the higher the price, the higher the likelihood of submitting the winning bid. This induces the convexity of $F_{I}$ ( $f_{1}$ is increasing).

For the seller side of the market, when $v=0$ the reverse argument applies; the informed wish to put more mass on lower prices, as it increases the likelihood of selling the worthless asset. This gives $G_{1}$ its concave shape ( $g_{\mathrm{I}}$ is decreasing). Similar intuitive arguments can be given for the determination of the shapes of $F_{\mathrm{u}}$ and $G_{\mathrm{u}}$. More formally:

Lemma 3: The equilibrium densities used by buyers to randomize bids are increasing and convex, while the equilibrium densities used by sellers to randomize their asking prices are decreasing and convex.

Proof: Differentiation of the equilibrium cdfs reveals the following

10 See Trueman (1988) for an altemative explanation of noise trading arising from the optimal strategies of investment fund managers. 


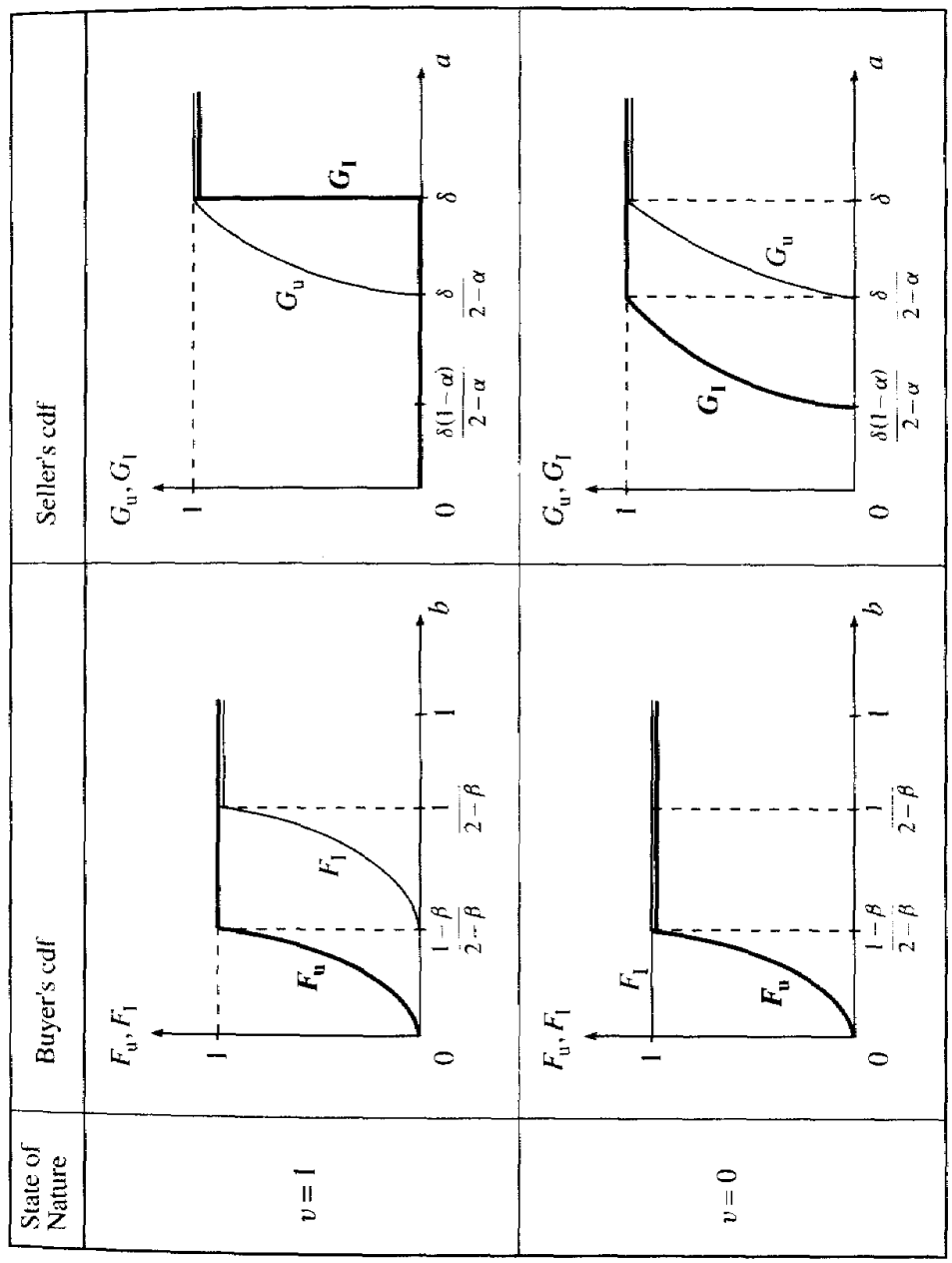

Fig. 1. 
densities for informed and uninformed buyers and sellers:

$$
\begin{aligned}
& f_{\mathrm{u}}(b)=\frac{\beta\left[\frac{1}{2}-b\right]^{-2}}{4(1-\beta)} ; \\
& f_{\mathrm{I}}(b)=\frac{(1-\beta)[1-b]^{-2}}{\beta(2-\beta)} ; \\
& g_{\mathrm{u}}(a)=\frac{\alpha \delta[2 a-\delta]^{-2}}{1-\alpha} ;
\end{aligned}
$$

and

$$
g_{\mathrm{I}}(a)=\frac{\delta(1-\alpha) a^{-2}}{\alpha(2-\alpha)}
$$

Thus, $\mathrm{d} f_{\mathrm{u}} / \mathrm{d} b>0$ and $\mathrm{d} f_{\mathrm{I}} / \mathrm{d} b>0$, whereas $\mathrm{d} g_{\mathrm{u}} / \mathrm{d} a<0$ and $\mathrm{d} g_{\mathrm{I}} / \mathrm{d} b$ $<0$. This proves that the densities for buyers are increasing functions of their bids, whereas the densities of sellers are decreasing functions of their asking prices. Moreover, $\mathrm{d}^{2} f_{\mathrm{u}} / \mathrm{d} b^{2}>0 ; \mathrm{d}^{2} f_{\mathrm{I}} / \mathrm{d} b^{2}>0$, $\mathrm{d}^{2} g_{\mathrm{u}} / \mathrm{d} a^{2}>0$, and $\mathrm{d}^{2} g_{\mathrm{I}} / \mathrm{d} b^{2}>0$, so that all of the densities are convex.

\section{The Specialist's Profits, the Bid-Ask Spread, and Asset Market Equilibrium}

The previous section established that there exist randomized bid and ask prices such that no individual trader has an incentive to change the mixed strategies given the strategies of other traders in the market. Moreover, all traders earn nonnegative expected profit. Following the literature on imperfectly competitive securities markets where the specialist is not passive but rather strategic (cf. Spiegel and Subrahmanyam, 1992), we now extend the notion of equilibrium to require that our passive specialist earns nonnegative expected profits. ${ }^{11}$ Since the specialist's profit is the bid-ask spread, this section may also be interpreted as an analysis of the expected spread. We show that, under

11 That this is a reasonable additional requirement for an equilibrium is evidenced by the fact that many computerized exchanges are privately held. For instance, AZX, Inc. is a privately held company that owns the Arizona Stock Exchange. If the exchange earned, on average, negative profits, the company would go bankrupt and the market would cease to exist. 
from its monopoly power. ${ }^{13}$ Similarly, if everyone is informed, $(\alpha=$ $\beta=1$ ), the specialist's profits are also $(1-\delta) / 2>0$, and traders earn zero profits.

Finding conditions under which the specialist's expected profits are positive in the presence of asymmetric information requires a more elaborate argument. First, note in Eq. (3) that, for a given $\delta$, the specialist's expected profits are minimized when the information partition is such that $\alpha=\beta=\theta$, where $\theta \equiv 2-\sqrt{2} \approx 0.59$. It also follows that this information partition maximizes the aggregate expected profits of informed traders. Evaluating Eq. (3) at this information partition, setting $E \pi=0$, and solving for $\delta$ gives us the critical value, $\delta^{*}$, such that the specialist's expected profits are zero under this information partition:

$$
\delta^{*}=\frac{2-3 \theta+2 \theta^{2}}{2+\theta-2 \theta^{2}} \approx 0.49 .
$$

Since Eq. (3) is decreasing in $\delta$ and the information partition $\alpha=\beta=\theta$ leads to the lowest possible expected profits for every $\delta$, it follows that $\delta<\delta^{*}$ is a sufficient condition for the specialist to earn positive expected profits for any configuration of informed and uninformed traders. ${ }^{14}$ Moreover, note that for any $\delta, \alpha, \beta \in(0,1)$, informed buyers and sellers earn positive expected profits, while uninformed traders earn zero expected profits. We summarize the implications of these findings in:

Proposition 2: Suppose buyers and sellers are sufficiently heterogemeous, in the sense that $\delta<\delta^{*}$. Then for any possible information partition (for every $\alpha, \beta \in[0,1]$ ), there exists a mixed-strategy equilibrium in the asset market where the specialist earns positive expected profits. Moreover, the specialist extracts all surplus except for the information tents earned by the informed traders. As the asymmetric information vanishes (as $\alpha$ and $\beta$ tend to zero or one), information rents vanish, and the specialist extracts all surplus.

The condition $\delta<\delta^{*}$ in Proposition 2 is a sufficient condition for

13 Of course, if traders could costlessly bypass the specialist and engage n direct exchange, they could earn positive profits. But one of the main easons securities markets exist is that the search and transactions costs of lirect exchange are so high as to make direct exchange unprofitable.

14 It follows that, for a given $\delta$, the expected bid-ask spread is minimized when $\alpha=\beta=\theta$. It is maximized, for a given $\delta$, when there is symmetric nformation $(\alpha=\beta=1$ or $\alpha=\beta=0)$. 
plausible conditions, the owner of the computerized trading system in. deed earns nonnegative profits. More surprisingly, we will show that $f_{0}$ : some information configurations, the passive specialist actually earn maximal profits.

Lemma 4: Given the Nash equilibrium bid and ask strategies of in formed and uninformed buyers and sellers, the expected profit of the specialist (or equivalently, the expected bid-ask spread) is

$$
E \pi=\frac{(1-\delta)}{2}-\frac{\beta(1-\beta)}{2-\beta}-\frac{\delta \alpha(1-\alpha)}{2-\alpha} .
$$

Proof: We present here a short proof ${ }^{12}$; an alternative proof, which useful because it decomposes expected profits into expected revenu: and costs, is presented in the Appendix.

The total expected profit in the market is $\frac{1}{2}(1-\delta)$. Thus it is suff. cient to establish that the second and third terms in Eq. (3) are the tota expected profits of all buyers and all sellers, respectively, participar ing in the auction. The expected profits of one randomly chosen burr competing in the auction are

$$
E \pi^{B}=\beta\left\{\frac{1}{2} E\left[\pi_{\mathrm{I}}^{b} \mid v=1\right]+\frac{1}{2} E\left[\pi_{1}^{b} \mid v=0\right]\right\}+(1-\beta) E \pi_{\mathrm{u}}^{b} .
$$

By Lemma $1, E\left[\pi_{1}^{b} \mid v=1\right]=\frac{1-\beta}{2-\beta}$, while $E\left[\pi_{1}^{b} \mid v=0\right]=E \pi_{v}^{b}=$ 0 . Hence, $E \pi^{B}=\frac{\beta(1-\beta)}{2(2-\beta)}$. Since there are two traders competing fo the right to buy at any instant in time, the total expected profits all buyers are $2 E \pi^{B}=\frac{\beta(1-\beta)}{2-\beta}$, which justifies the second term Eq. (3). Similarly, one can show that the expected profits of all trader: competing for the right to sell at any instant in time are $\frac{\delta \alpha(1-\alpha)}{2-\alpha}$. :

Given the formula for expected profits given in Eq. (3), it is clei that there exist values of $\delta, \beta$, and $\alpha$ such that the expected profits of thi specialist are nonnegative. When everyone is uninformed $(\alpha=\beta=0$. the specialist's profit (the bid-ask spread) is $(1-\delta) / 2>0$, while buyen and sellers earn profits of zero. In this case, the specialist extracts al surplus from the market, despite its passive nature. The reason sterti:

12 We are grateful to $\mathrm{Qi} \mathrm{Li}$ for suggesting this proof. 
the specialist to earn positive expected profits for any possible information partition. Note, however, that for specific information partitions, the specialist may earn positive profits even if $\delta>\delta^{*}$. But even in these cases, there must be sufficient heterogeneity ( $\delta$ cannot be too close to 1). For instance, suppose each side of the market has equal numbers of informed and uninformed traders: $\alpha=\beta=1 / 2$. In this case, the specialist's expected profits are $E \pi=(1-2 \delta) / 3$; uniformed traders earn zero while informed buyers and sellers in the aggregate earn information rents of $(1+\delta) / 3$. In this instance the specialist's expected profits will be positive if $1 / 2>\delta>\delta^{*}$. But with too little heterogeneity among buyers and sellers (i.e., if $\delta>1 / 2$ ), expected profits would be negative.

Thus, in situations where there is not sufficient heterogeneity between buyers and sellers, a specialist would earn negative economic profits for some information configurations. In these cases, an equilibrium in the more general sense would fail to exist because the computerized market for the asset would not exist. This result is similar to Spiegel and Subrahmanyam's (1992) results for the case of a strategic specialist. They show that a linear equilibrium exists in the absence of noise traders only if there is sufficient heterogeneity among traders in their risk-preferences. Our results suggest that computerized exchanges cannot serve all types of assets - only those assets where there is considerable heterogeneity in valuations of assets. This result seems consistent with the fact that the major computerized trading systems (such as Globex and RAES) currently trade only futures or options contracts - financial instruments where buyers and sellers tend to have large differences in opinions about the valuation of the underlying asset.

One of the striking features of these types of computerized markets is that the monopoly power enjoyed by the specialist allows it to earn positive profits, even though the specialist behaves non-strategically. In the case of symmetric information, the passive specialist extracts all of the gains from exchange. In the case of asymmetric information, the traders with better information earn an information rent, but the specialist extracts all the remaining surplus. This would appear to explain why there has been a recent surge in computerized exchanges, and why the exchanges thrive even though the algorithms used to match buyers and sellers are simple and non-strategic. By committing to non-strategic behavior - a commitment which is credible due to government regulatory bodies that audit computerized exchanges - computerized exchanges may actually extract all surplus. 


\section{Information Acquisition}

Up until now, we have assumed that some traders are endowed with better information than others. This assumption implied that informed traders earn information rents, which reduce the profits earned by the passive specialist. In general, the values of $\alpha$ and $\beta$ will be endogenously determined as traders optimally seek to obtain information. In order to allow for an endogenous determination of informed and uninformed market participants, we introduce:

Assumption 8: There is a market for information so that traders may endogenously determine whether or not to become informed. Let $B$ be the cost to a buyer of becoming informed, and let $S$ be the cost to a seller of becoming informed.

Notice that this assumption is perfectly general in that information costs may be identical on both sides of the market $(B=S)$, or different $(B \neq S)$. In the case of stock transactions, one might expect $S<B$. since companies send annual reports to stockholders of record but others must acquire this information on their own.

Assuming that information is accessible to all traders, additional traders will acquire information so long as the expected profits of doing so exceed information costs. In equilibrium, traders with information must earn the same net profits as those without information (which is zero); otherwise, it would pay uninformed traders to become informed. Since uninformed traders earn zero expected profits, this implies that the $e x$ ante gain to a buyer of becoming informed is, in equilibrium.

$$
\frac{1}{2} E\left[\pi_{1} \mid v=0\right]+\frac{1}{2} E\left[\pi_{1} \mid v=1\right]-B=0
$$

or

$$
0+\frac{1}{2}\left[\frac{1-\beta}{2-\beta}\right]-B=0
$$

Similarly, the ex ante gain to a seller of becoming informed is

$$
\frac{1}{2} E\left[\pi_{I} \mid v=0\right]+\frac{1}{2} E\left[\pi_{I} \mid v=1\right]-S=0
$$

Or

$$
\frac{1}{2}\left[\frac{\delta(1-\alpha)}{2-\alpha}\right]+0-S=0 .
$$


Solving for $\alpha$ and $\beta$ in Eqs. (5) and (7) yields:

Proposition 3: If buyers and sellers can acquire full information at a cost of $B$ and $S$, respectively, then the equilibrium fraction of informed buyers is

$$
\beta^{*}=\frac{1-4 B}{1-2 B}
$$

and the equilibrium fraction of informed sellers is

$$
\alpha^{*}=\frac{\delta-4 S}{\delta-2 S} .
$$

Moreover, the ex ante profits to informed and uninformed buyers and sellers are zero.

As would be expected, the proposition reveals that the number of informed traders on a given side of the market is a decreasing function of the cost of information. Moreover, Eqs. (4) and (6) indicate that, when there is a market for information, the traders earn zero expected profits. The information rents earned by informed traders exactly offset the cost of their information. In this case, only the specialist will earn profits (provided, of course, that there is sufficient heterogeneity in buyers and sellers).

The analysis above reveals the existence of an equilibrium in asset markets characterized by costly information. The equilibrium involves mixed strategies, and as a consequence, the bid and ask prices - as well as the bid-ask spread - are random variables induced by the equilibrium distribution of bid and ask prices. If everyone has access to information, the equilibrium number of informed and uninformed traders is endogenously determined, and in equilibrium both informed and uninformed traders earn zero economic profits. The reason is simple: if informed traders make positive expected profits, then uninformed traders have an incentive to become informed. Since the profits of informed traders are a decreasing function of the number of informed competitors, "entry" into the realm of the informed drives expected profits to zero. On average, the rent earned by the informed exactly offsets the cost of the information.

If some traders have privileged access to information while other traders cannot gain information, then the number of informed and uninformed will be exogenous. In this instance an equilibrium still exists in the asset market with the asymmetric information, but the informed traders earn economic rents due to their information advantage. 


\section{The Information Content of Prices}

Because the prices reported on computerized exchanges are the bid and ask transactions prices, and one does not know the identity of the buyer or seller (specifically, whether the last transaction was made by an informed or uninformed trader), it is of interest to examine the ex-post informational content of the winning bid and ask prices on a computerized exchange. We consider the buyer side of the market; the analysis for the seller side is analogous.

Suppose the winning bid is in the interval $[0,(1-\beta) /(2-\beta)]$. Then with probability one the winning bid was submitted by an uninformed buyer, for informed buyers always submit bids above $(1-\beta) /(2-\beta$ ) when $v=1$, and bid zero if $v=0$. There are exactly two ways a winning bid can be submitted by an uninformed buyer: either two uninformed bidders bid against one another, in which case the winning bid reveals nothing about the true value of the asset, or the uninformed bidder outbids an informed buyer. In this latter case the true value of the asset is zero. Hence the only way the asset can be of value $(v=1)$ when the bid is in this interval is if the winning bid resulted from two uninformed traders. Since the probability two uninformed buyers bid against one another is $(1-\beta)^{2}$, the expected value of the asset, conditional on the winning bid being in the interval $[0,(1-\beta)]$ $(2-\beta)]$ is

$$
E\left\{v \mid b \in\left[0, \frac{1-\beta}{2-\beta}\right]\right\}=\frac{(1-\beta)^{2}}{2} .
$$

By similar arguments $E\{v \mid b=0\}=0$ and $E\{v \mid b>(1-\beta) /(2-\beta)\}$ $=1$.

The fact that these expectations differ reveals that the winning bid (the reported asset price) does contain information. But since traders must submit bids before this information is reported, this information cannot be used by traders in submitting their bids. This is why an equilibrium exists in this type of computerized market, but may fail to exist in models where there is a menu price for an asset and no exogenous noise. ${ }^{15}$

15 Importantly, the above analysis presumes that the informed traders used their information to its fullest potential at a single instant in time; unlike Mirman and Samuelson (1988), the above analysis does not allow traders to manipulate prices over time by getting in and out of the market quickly upon demand. 


\section{Conclusion}

We have examined a computerized market infested with asymmetric information. The institutional structure of the market is such that a computerized specialist is programmed to buy from the person asking the lowest price and sell to the person submitting the highest bid. This institutional structure is consistent with several existing computerized exchanges, most notably the Globex and RAES systems. The key implications of this type of market institution are:

1. Even in the presence of asymmetric information, risk neutrality, and the absence of noise traders, an equilibrium exists in the asset market.

2. Transactions prices and the bid-ask spread fluctuate randomly, since the equilibrium involves mixed-strategies.

3. Traders with privileged access to information earn positive expected profits, while those without access earn zero expected profits. The computerized specialist, though passive, extracts all surplus except the information rents accruing to the informed traders.

4. When everyone has equal access to costly information, the number of informed and uninformed traders is endogenous, and all traders earn zero expected profits. In this case, the specialist extracts all surplus, net of the information costs paid by the traders.

5. The number of informed traders is a decreasing function of information costs.

6. For a market to exist (that is, for the specialist to earn nonnegative profits), there must be sufficient heterogeneity between buyers and sellers.

7. Buyers bid high prices more frequently than they bid low prices.

8. Sellers ask low prices more frequently than they ask high prices.

9. In the limiting case of perfect, symmetric information (that is, when $\alpha$ and $\beta$ are one), all traders earn zero profits, the asset price is perfectly revealing, and the computerized specialist extracts all surplus.

10. In the limiting case of imperfect but symmetric information (that is, when $\alpha$ and $\beta$ are zero), all traders earn zero profits and the computerized specialist extracts all surplus.

11. In the presence of asymmetric information, transactions prices are perfectly revealing only if prices are extremely "high" or "low." When prices are in the intermediate range, they are only partially revealing.

In closing, we point out that our model assumes that the computerized exchange is a monopoly; traders have no outside options except to 
trade on the exchange. This assumption allows one to directly compare the results in our passive computerized market with existing results on monopoly exchanges where the specialist behaves strategically. In reality, computerized exchanges coexist, although at present they trade different assets. It would be interesting to extend this analysis to examine the implications of coexisting computerized exchanges. Due to the passive nature of the specialist on computerized exchanges, this task would appear more tractable than extending the literature on strategic specialists to scenarios where traders can choose to buy or sell on different exchanges (e.g., oligopoly specialists).

\section{Appendix}

We present here an alternative proof to Lemma 4, which is useful because it decomposes profits into revenues and costs. Specifically, we will show that the specialists profits are given by $E \pi=E R-E C$. where the expected revenues of the specialist are

$$
E R=\frac{1}{2}\left[\frac{1-(1-\beta)(2 \beta-1)}{2-\beta}\right]
$$

and the expected costs are

$$
E C=\frac{\delta}{2}\left[\frac{(2 \alpha+1)(1-\alpha)+1}{2-\alpha}\right] .
$$

Proof: Since the specialist sells high and buys low, the expected revenues of the specialist are based on the maximum order statistic of bids submitted by buyers; the expected costs are based on the minimum order statistic of the asking prices submitted by sellers. The expected revenues of the specialist are given by

$$
\begin{aligned}
E R= & \frac{1}{2}\left\{\beta^{2} \cdot 0\right. \\
& \left.+(1-\beta)^{2} \int_{i(\mathrm{u})} 2 b F_{\mathrm{u}} \mathrm{d} F_{\mathrm{u}}(b)+2 \beta(1-\beta) \int_{i(\mathrm{u})} b \mathrm{~d} F_{\mathrm{u}}(b)\right\} \\
& +\frac{1}{2}\left\{\beta^{2} \int_{i(\mathrm{l})} 2 b F_{\mathrm{I}} \mathrm{d} F_{\mathrm{I}}(b)+(1-\beta)^{2} \int_{i(\mathrm{u})} 2 b F_{\mathrm{u}} \mathrm{d} F_{\mathrm{u}}(b)\right. \\
& \left.+2 \beta(1-\beta) \int_{i(\mathrm{I})} b \mathrm{~d} F_{\mathrm{I}}(b)\right\} .
\end{aligned}
$$


The above equations have the following interpretation. Half of the time, the asset is worthless, and the expected revenues of the specialist are given by the terms in the first pair of curly brackets. With probability $\beta^{2}$, two informed traders will compete for the right to buy the asset, and given the equilibrium strategies, they bid zero for the asset. With probability $(1-\beta)^{2}$, two uninformed traders compete for the asset, and the expected bid is given by the expectation of the maximum order statistic of the two uninformed buyer's bids, namely $\int_{i(u)} 2 b F_{\mathrm{u}} \mathrm{d} F_{\mathrm{u}}(b)$. With probability $2 \beta(1-\beta)$, an informed trader will compete against an uninformed trader. Since the informed trader bids zero in this instance, the uninformed trader submits the winning bid with probability one, and the expected bid is simply $\int_{i(\mathrm{u})} b \mathrm{~d} F_{\mathrm{u}}(b)$.

The other half of the time, the asset value is unity, and the expected revenues of the specialist are given by the terms in the second pair of curly brackets. With probability $\beta^{2}$, two informed traders will compete for the right to buy the asset, and the expected bid is given by the expectation of the maximum order statistic of their bids, namely $\int_{i\left(\Gamma_{1}\right.} 2 b F_{1} \mathrm{~d} F_{I}(b)$. With probability $(1-\beta)^{2}$, two uninformed traders compete for the asset, and the expected bid is given by the expectation of the maximum order statistic of the two uninformed buyer's bids, which is $\int_{i(\mathrm{u})} 2 b F_{\mathrm{u}} \mathrm{d} F_{\mathrm{u}}(b)$. With probability $2 \beta(1-\beta)$, an informed trader will compete against an uninformed trader. Since the informed trader bids according to $F_{1}(b)$ and, in this instance, submits the winning bid with probability one, the expected bid is simply $\int_{i(l)} b \mathrm{~d} F_{\mathbf{J}}(b)$.

Similarly, letting $j(\mathrm{I})=\left[\frac{\delta(1-\alpha)}{2-\alpha}, \frac{\delta}{2-\alpha}\right]$ and $j(\mathrm{u})=\left[\frac{\delta}{2-\alpha}, \delta\right]$, the expected costs of the specialist are

$$
\begin{aligned}
E C= & \frac{1}{2}\left\{\alpha^{2} \int_{j(\mathrm{l})} 2 a\left[1-G_{\mathrm{I}}\right] \mathrm{d} G_{\mathrm{I}}\right. \\
& +(1-\alpha)^{2} \int_{j(\mathrm{u})} 2 a\left[1-G_{\mathrm{u}}\right] \mathrm{d} G_{\mathrm{u}}(a) \\
& \left.+2 \alpha(1-\alpha) \int_{j(\mathrm{l})} a \mathrm{~d} G_{\mathrm{I}}(a)\right\} \\
& +\frac{1}{2}\left\{\alpha^{2} \delta+(1-\alpha)^{2} \int_{j(\mathrm{u})} 2 a\left[1-G_{\mathrm{u}}\right] \mathrm{d} G_{\mathrm{u}}(a)\right. \\
& \left.+2 \alpha(1-\alpha) \int_{j(\mathrm{u})} a \mathrm{~d} G_{\mathrm{u}}(a)\right\} .
\end{aligned}
$$


Straightforward, but tedious, calculations using the change of variable technique of integration reveals:

$$
\begin{aligned}
& E R=\frac{1}{2}\left\{0+\left[\frac{1}{2}-\frac{3 \beta}{2}+\beta^{2}+\frac{\beta^{2}}{4} \log \left(\frac{2-\beta}{\beta}\right)\right]\right. \\
& \left.+\left[\beta-\beta^{2}-\frac{\beta^{2}}{2} \log \left(\frac{2-\beta}{\beta}\right)\right]\right\} \\
& +\frac{1}{2}\left\{\left[\frac{2 \beta}{2-\beta}+\beta^{2}-2 \beta-\frac{2(1-\beta)^{2}}{2-\beta} \log (1-\beta)\right]\right. \\
& +\left[\frac{1}{2}-\frac{3 \beta}{2}+\beta^{2}+\frac{\beta^{2}}{4} \log \left(\frac{2-\beta}{\beta}\right)\right] \\
& \left.+\left[2 \beta-2 \beta^{2}+\frac{2(1-\beta)^{2}}{2-\beta} \log (1-\beta)\right]\right\} \\
& =\frac{1}{2}\left[\frac{1-(1-\beta)(2 \beta-1)}{2-\beta}\right] \text {. } \\
& E C=\frac{1}{2}\left\{\left[\frac{2 \delta(1-\alpha)^{2}}{2-\alpha} \log (1-\alpha)-\frac{2 \delta(1-\alpha)^{2}}{2-\alpha}+\frac{2 \delta(1-\alpha)}{2-\alpha}\right]\right. \\
& +\left[\frac{\delta}{2}-\frac{\alpha \delta}{2}-\frac{\delta \alpha^{2}}{4} \log \left(\frac{2-\alpha}{\alpha}\right)\right] \\
& \left.-\left[\frac{2 \delta(1-\alpha)^{2}}{2-\alpha} \log (1-\alpha)\right]\right\} \\
& +\frac{1}{2}\left\{\alpha^{2} \delta+\left[\frac{\delta}{2}-\frac{\alpha \delta}{2}-\frac{\delta \alpha^{2}}{4} \log \left(\frac{2-\alpha}{\alpha}\right)\right]\right. \\
& \left.+\left[\frac{\alpha^{2} \delta}{2} \log \left(\frac{2-\alpha}{\alpha}\right)-\alpha^{2} \delta+\alpha \delta\right]\right\} \\
& =\frac{\delta}{2}\left[\frac{(2 \alpha+1)(1-\alpha)+1}{2-\alpha}\right] \text {. }
\end{aligned}
$$

Simple algebra reveals that $E R-E C$ can be rewritten as $E \pi$ given in Eq. (3) of the text, as of course it should. 


\section{Acknowledgements}

We are grateful to Jürgen Dennert, Qi Li, and the perceptive comments of the referees for pointing us in the right direction.

\section{References}

Baye, M. R., and Cosimano, T. (1990): "Choosing Sides in Matching Games:

Nash Equilibria and Comparative Statics." Economica 57: 283-293.

Baye, M. R., Kovenock, D., and de Vries, C. G. (1992): "It Takes Two-toTango: Equilibria in a Model of Sales." Games and Economic Behavior 4: 493-510.

Berkman, H. (1990): "Intraday Patterns in Quoted Spread on the Options Exchange and the Influence of the Limit-Order Book." Revue Economique 41: 789-798.

Cohen, K. J., Maier, S. F., Schwartz, R. A., and Whitcomb, D. K. (1986): The Microstructure of Securities Markets. Englewood Cliffs, NJ: Prentice-Hall. Copeland, T.E., and Galai, D. (1983): "Information Effects of the Bid-Ask Spread." Journal of Finance 38: 1457-1469.

Domowitz, I. (1990): "The Mechanics of Automated Trade Execution Systems," Journal of Financial Intermediation 1: 167-194.

Easley, D., and O'Hara, M. (1987): "Price, Trade Size, and Information in Securities Markets." Joumal of Financial Economics 19: 69-90.

— (1991): "Order Form and Information in Securities Markets." Joumal of Finance 46: 905-927.

- (1993): "Market Microstructure." In Finance, edited by R. A. Jarrow, V. Maksimovic, and W.T. Ziemba. (Handbooks in Operations Research and Management Science.) Amsterdam: North-Holland (forthcoming).

Glosten, L. R., and Milgrom, P. R. (1985): "Bid, Ask and Transaction Prices in a Specialist Market With Heterogeneously Informed Traders." Journal of Financial Economics 14: 71-100.

Gould, J. P., and Verrecchia, R. E. (1985): "The Information Content of Specialist Pricing." Journal of Political Economy 93: 66-83.

Grossman, S. J., and Stiglitz, J. E. (1980): "On the Impossibility of Informationally Efficient Markets." American Economic Review 70: 393-408.

Kyle, A. S. (1985): "Continuous Auctions and Insider Trading." Econometrica 53: $1315-1335$.

- (1989): "Informed Speculation with Imperfect Competition." Review of Economic Studies 56: 317-356.

Madhavan, A. (1992): "Trading Mechanisms in Securities Markets." Journal of Finance 47: 607-641.

Mirman, L. J., and Samueison, L. (1989): "Information and Equilibrium with Inside Traders." Economic Joumal 99: 152-167.

O'Hara, M., and Oldfield, G. (1986): "The Microeconomics of Market Making." Joumal of Financial and Quantitative Analysis 21: 361-376. 
Rock, K. (1990): "The Specialist's Order Book and Price Anomalies." Mimeo, Harvard University.

Spiegel, M., and Subrahmanyam, A. (1992): "Informed Speculation and Hedg. ing in a Noncompetitive Securities Market." Review of Financial Studies 5: $307-329$.

Trueman, B. (1988): "A Theory of Noise Trading in Securities Markets." Journal of Finance 43: 83-95.

Addresses of authors: Michael R. Baye, Department of Economics, The Pennsylvania State University, University Park, PA 16802-3305, USA; - Ann Gillette, School of Business, Indiana University, 801 West Michigan Street, Indianapolis, IN 46202-5151, USA; - Casper G. de Vries, Tinbergen Institute. Erasmus Universiteit Rotterdam, Oostmaaslaan 950, 3063 DM Rotterdam, The Netherlands. 
Copyright of Journal of Economics is the property of Springer Science \& Business Media B.V.. The copyright in an individual article may be maintained by the author in certain cases. Content may not be copied or emailed to multiple sites or posted to a listserv without the copyright holder's express written permission. However, users may print, download, or email articles for individual use. 